\title{
Mathematics Teachers' Beliefs about Inquiry-based Learning after a Professional Development Course-An International Study
}

\author{
Katja Maass ${ }^{1}$, Malcolm Swan ${ }^{2}$, Anna-Maria Aldorf ${ }^{1}$ \\ ${ }^{1}$ University of Education Freiburg, Germany \\ ${ }^{2}$ Shell Centre, University of Nottingham, UK \\ Correspondence: Katja Maass, University of Education Freiburg, Germany.
}

Received: June 20, 2017

doi:10.11114/jets.v5i9.2556
Accepted: July 26, 2017 Online Published: July 27, 2017

URL: https://doi.org/10.11114/jets.v5i9.2556

\begin{abstract}
Inquiry-based learning (IBL) is a more student-centered approach to mathematics teaching that is recommended by many policy and curriculum documents across Europe. However, it is not easy for teachers to change from a more teacher-centered way of teaching to inquiry-based teaching as this involves a change of their role in class. Professional development courses are one way to help teachers with this endeavor. Within the discussion of effective professional development, beliefs are often named as an important influencing factor. In this respect, much research has been carried out on how beliefs on mathematics teaching impact the outcomes of the course. However, there has been much less research on what beliefs mathematics teachers develop on inquiry-based learning and how this might impact their (perceived) classroom teaching. Therefore, this paper presents an international research study carried out within the European Project Primas, in which professional development courses on inquiry-based learning were conducted in 12 countries. Using the case-study approach, this paper aims at answering the following questions: 1 . What kind of beliefs about IBL do mathematics teachers across Europe develop? 2. How do these beliefs relate to teachers' perceived enactments of IBL?
\end{abstract}

Keywords: teachers' beliefs, inquiry-based learning, professional development, case studies, teachers' beliefs on inquiry-based learning

\section{Introduction}

Europe faces an alarming decline in young peoples' interest in mathematics and science (Rocard et al., 2007). As one consequence, a well-known European report, the Rocard's report (Rocard et al., 2007) recommended inquiry-based learning (IBL) as opposed to teacher-centered transmission-based teaching. This led the EU to fund research projects to promote the implementation of IBL in day-to-day math and science classes-here we focus on mathematics. One reason for these financial grants was that it is by no means straight-forward for teachers to change their way of teaching from a transmission-based way to a student-centered way like IBL. IBL seems to be a particular challenge to teachers' beliefs about mathematics teaching, as IBL requires a change of role in class. The teacher's role changes from a transmitter of knowledge to a moderator of learning processes (Swan, 2005, 2007) as a closer look on the two teaching approaches reveals:

In transmission-based mathematics classes the teacher points out what must be observed, provides the questions, demonstrates the methods to be used, checks results, and so on while students are left only to employ well-rehearsed procedural techniques (Mullis, Martin \& Foy, 2008; Stigler, Gonzales, Kawanaka, Knoll \& Serrano, 1999).

In IBL lessons students are invited to observe phenomena and create their own questions, select mathematical approaches; carry out hands-on experiments, create representations to clarify relationships, seek explanations, interpret and evaluate solutions, and communicate their solutions (Dorier \& Maass, 2012). This process is cyclic in nature (Artigue \& Blomhoej, 2013) and we refer to it here as the inquiry circle.

Thus, if we want teachers to change their way of teaching, they need support. One means of providing this support is professional development (PD).

In the last decades, much research has been done in relation to professional development (Roesken-Winter, Hoyles \& Blömeke, 2015) and related theory-based quality criteria for effective PD have been developed (cf. Joubert \& 
Southerland, 2009; Barzel \& Selter, 2015). These criteria include among others, that PD should take into account all facets of teachers' competences and also foster teachers' self-reflection on their beliefs about mathematics teaching. The latter seems to be particularly important, as research has shown that these beliefs have an important impact on what a teacher actually implements in their day-to-day teaching (Roesken-Winter, Schüler, Stahnke \& Blömeke, 2015).

In relation to IBL and the above mentioned challenges teachers face, we have to be aware that the "task of preparing teachers for inquiry teaching is much bigger than the technical matters [...] the matter must be addressed [...] at a level that includes central attention to beliefs and values." (Anderson, 2002, p. 8).

We know that teachers' beliefs on mathematics teaching in general range from considering mathematics teaching as explaining mathematical rules and algorithms and students' mastering well-rehearsed examples to considering mathematics as problem-solving and supporting their students in solving these problems (Maass, 2009, Pehkonen \& Törner, 1996). Additionally, we know that teachers' prior beliefs on mathematics teaching influence their perceived enactment of a more student-centered way of teaching (Maass, 2011). In relation to mathematical modeling, a student-centered teaching approach with many common features to inquiry-based learning (cf. Artigue \& Blomhoej 2013), Maass (2011) identified two types of teachers who argued for or against modeling in relation to their prior beliefs. Apparently, teachers with more transmission-based beliefs about mathematics teaching perceive more challenges for the implementation of modeling and find more reasons for not implementing it than teachers focusing on students' acquiring problem-solving competences.

In this paper we focus on another type of belief which seems to be equally important regarding teachers' implementation of IBL, namely the beliefs teachers develop about the teaching approach concerned, in this case IBL. We do not know much about mathematic teachers' beliefs on IBL. There are some small-scale national studies in science education (Panjwani, 2015, Marshall \& Smart, 2013) that lead to the conclusion that teachers' interpretation of IBL can be very different from the conveyed definition of IBL, meaning that the intended outcome is very different from the real outcome. We know even less on how this might impact the enactment in the classroom. And more importantly, we know almost nothing about the respective situation in mathematics education. In contrast to science, pure mathematics is deductive and is not necessarily connected to reality. Therefore mathematics has specific characteristics which can influence teachers' beliefs on mathematics teaching (Maass, 2009). Consequently, the question of how mathematics teachers interpret IBL after a PD course seems to be a vital question for their implementation of IBL and it has not been answered yet.

This paper aims to close this gap. We will present a research study which examined the beliefs of 17 mathematics teachers about inquiry-based learning who took part in PD courses across Europe. The PD course aimed at supporting mathematics (and science) teachers in implementing IBL in their day-to-day teaching. The course design followed research-based criteria for PD. The explorative evaluation of case-studies from 17 mathematics teachers across 11 countries allowed us to gain in-depth insights into their interpretations of IBL. Therefore, in this paper we focus on the following explorative research questions:

1) What beliefs about IBL did mathematics teachers across Europe develop?

2) How do these beliefs relate to teachers' perceived enactments of IBL?

The research study was carried out within the project Primas (Promoting inquiry in mathematics and science education across Europe). Primas was one of the first projects within the Seventh Framework Program of the EU, which received funding following on from the Rocard-Report (Rocard et al., 2007). In Primas, between 2010 and 2013, 14 universities from 12 countries (Cyprus, Denmark, England, Germany, Hungary, Malta, Netherlands, Norway, Romania, Slovakia, Spain, Switzerland) worked together to promote the implementation of IBL in mathematics and science. Primas developed materials for direct use in class and for PD. In addition, the project ran PD activities in each of the partner countries (see Maass \& Doorman, 2013).

\section{Theoretical Background}

\subsection{Inquiry-based Learning (IBL)}

Historically, the importance of inquiry in education is generally attributed to the American educator John Dewey (18591952). He saw the importance of inquiry in a child's attitude towards science (Dewey, 1916). Dewey's perspective on education implies a practice of teaching based on projects closely linked to students' lives and interests, and to the development of inquiring minds. In the times of Dewey, IBL concerned sciences rather than mathematics. In relation to science, one major event was the publication of the National Science Education Standards in the USA in 1996 (National Research Council, 1996). From there, a wide spectrum of IBL approaches developed (Barrow, 2006), with various definitions that the revised National Science Education Standards (NSES) in 2000 tried to summarize in five points (National Research Council, 2000, p 27): 
- $\quad$ students create their own scientifically oriented questions;

- $\quad$ students give priority to evidence in responding to questions;

- $\quad$ students formulate explanations from evidence;

- $\quad$ students connect explanations to scientific knowledge;

- $\quad$ students communicate and justify explanations.

The focus on inquiry in mathematics education is more recent. It is based on the increasingly shared view that mathematics and sciences education are closely connected, that mathematics is not purely deductive and that mathematical concepts may be grasped through some experimental practice.

Although the term IBL is a more recent one in mathematics education several research theories in the field can be linked to IBL as Artigue and Blomhoej (2013) clarified by reviewing different teaching approaches in mathematics education, such as problem solving and mathematical modeling and comparing them with IBL.

The objectives of IBL are the development of process-oriented competences that prepare students for lifelong learning and a deeper appreciation of the nature of mathematical reasoning in the world around them (Artigue \& Blomhoej, 2013).

However, not all researchers see IBL as a favorable teaching approach. For example, Sewall (2000) points out that IBL lessons are over-emphasized at the expense of focused and guided lessons with a clear sense of direction. These critiques can be seen in relation to the many definitions that exist regarding IBL. An important difference in these definitions is the degree of autonomy given to students in the selection of problems and in the inquiry process itself (Artigue \& Blomhøj, 2013). Meta-studies on IBL research indeed seem to show that more guided approaches to IBL in which the teacher takes an active role in the inquiry-process and challenges students with effective questions seem to have better impact on students learning than discovery approaches in which the teacher takes a passive role (Alfieri, Brooks, Aldrich \& Tenenbaum 2011, Minner, Levy, \& Century 2011, Bruder \& Prescott 2013, Swan, 2006; Hmelo-Silver, Duncan \& Chinn, 2006). Therefore in our approach to inquiry-based learning, we refer to more guided inquiry in which the teacher takes an active role in students learning.

The pedagogical challenges of IBL are therefore clear: Teachers are required to shift from a transmission approach towards a collaborative orientation, in which students work together with the teacher on challenging tasks. Here, the teacher's active role includes making constructive use of students' prior knowledge, challenging students through probing questions, and encouraging the discussion of alternative viewpoints, etc. (Dorier \& Maass, 2012; Swan, 2006).

Due to different understandings of IBL in the theoretical discussion and different perspectives of the countries involved in Primas, it seemed important to develop a common definition of IBL which could also be used in the PD courses while conveying a clear picture of IBL to teachers. Fig. 1 shows our agreed definition. This definition comprises the aspects of (1) teacher guidance, (2) valued outcomes, (3) classroom culture, (4) types of questions, and (5) what students do. Aspect 1 refers to teachers' active role, aspect 2 to the above discussed objectives, aspect 4 to Dewey, and aspect 5 to the NSRS definition, all rephrased for use in class. Aspect 3 refers to classroom culture, and considers in particular Dewey's and the NSES' definition of IBL.

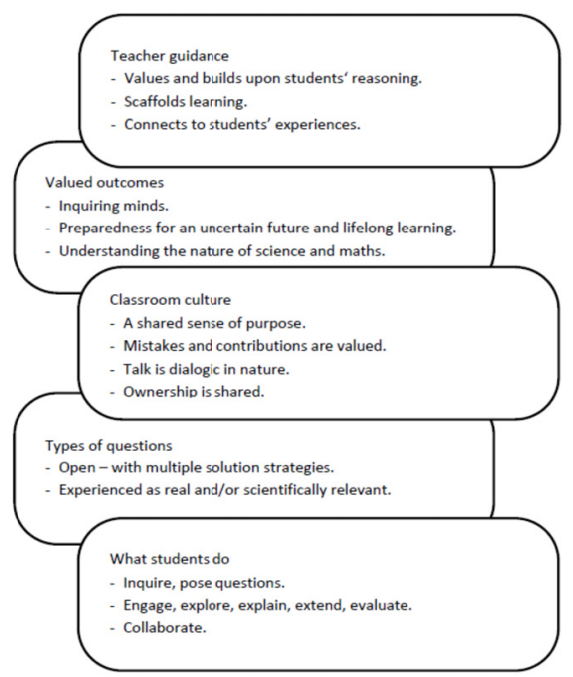

Figure 1. Ingredients of IBL within Primas 
Following on from our understanding of IBL, it can be implemented in class either when dealing with big open projects or with small tasks more connected to the curriculum. The following two Primas tasks illustrate the difference:

Task 1: On the 25th of April, 2006, the Spanish party in the opposition presented in the congress 4.000 .000 signatures against a new law promoted by the government.

All Spanish newspapers published pictures with the big boxes and the 10 vans needed to transport the sheets of paper to the congress. Do you think there was a political intention behind this staging or were all these boxes and vans really necessary to carry the 4000000 signatures? (See Fig. 2)

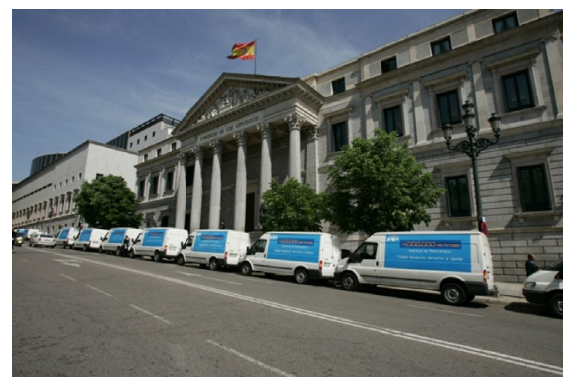

Figure 2. Vans as shown in the newspaper

Task 2: Which is the odd one out? Give reasons. Are there several possibilities?

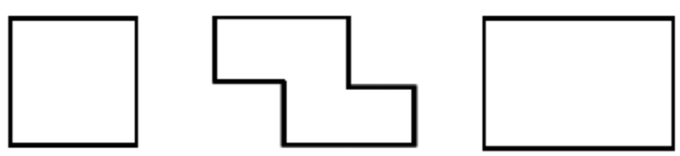

Figure 3. Three figures for Task 2

Both tasks contribute to students learning when they work in an inquiry-based way, but at very different levels. Task 1 is a very open task, which involves estimations on the number of signatures per paper, the height of the stacks of paper, and assumptions on how they will be packed. There are different paths to solutions, either working with the cargo area of the van, its volume, or even with the admissible total weight. A teacher using the task has to accept this and cannot prescribe that this will be a lesson on volumes, for example. Additionally, dealing with this task will take about 45-90 min. Task 2, however, may only need 10-15 minutes and has a relatively clear focus on rectangles and their definitions. It is inquiry-based, though, as several solutions are possible and students learn to give reasons.

In our understanding of IBL both tasks are valuable for the following reasons: (1) students need to learn to solve big problems, (2) time does not always allow doing so, and (3) sometimes a more focused proceeding as in task 2 is necessary.

\subsection{Teachers' Beliefs about IBL}

Generally speaking, teachers' beliefs are their relatively long-standing subjective knowledge of certain objects and the attitudes linked to that knowledge (Pehkonen \& Törner, 1996). Both beliefs and knowledge are organized in clusters. A belief can never exist completely independently of other beliefs (Green, 1971). Beliefs can be of different importance to people: Key beliefs are referred to as central, the less important ones as peripheral. The latter are considered to be easier to change than central ones (Furenghetti \& Pehkonen, 2002). While beliefs are complex in nature, certain types of them can be distinguished (Törner, 2002). These are, for example, beliefs about mathematics and its teaching, beliefs about the roles of teachers, etc.

The close connection between teachers' beliefs about teaching and their enacted teaching is commonly agreed (see e.g. Stahnke, Schuler, Roesken-Winter, 2016). However, the kind of relationship between beliefs and the enacted classroom practices has not been fully identified to date. Some studies suggest that beliefs have an influence on classroom practices (e.g., Schoenfeld, 1992), whilst others (e.g., Swan \& Swain, 2010) argue that rather than having an influence on practice, beliefs are more the result of practice. Also, not all studies suggest a linear relationship between beliefs and classroom practice. For example, Hoyles (1992) found the two aspects to be incompatible and argued that beliefs also depend on the situation in which they are expressed; she subsequently talks of situated beliefs.

Meanwhile, the discussion has turned away from such linear change models to a model combining different influencing aspects known as the interconnected model (Clarke \& Hollingsworth, 2002.). This model explains teacher professional growth in terms of domains that are connected through mediating processes. The domains are: (1) the personal domain (teacher knowledge, beliefs, and attitudes); (2) the domain of practice (professional experimentation); (3) the domain of 
consequence (salient outcomes); and (3) the external domain (sources of information, stimulus, or support).

By the same token, Schoenfeld (2011, p. xiv) moved away from a linear connection by arguing that what teachers do in classrooms is a function of their resources (their knowledge in terms of available material), goals and orientations (their beliefs, values, etc.), which - if known - can help to explain teachers' actions.

Summing up, we do not assume a linear connection between beliefs and classroom practices but acknowledge a connection within a large system of connected factors. Nowadays, "The importance of beliefs for the teaching and learning of mathematics is widely recognized among mathematics educators." (Roesken, Pepin, \& Törner 2011, p. 451).

Unfortunately, beliefs are often hard to change (Törner, 2002), or as Sowder (2007) said, “... many of teachers' core beliefs need to be challenged before change can occur"' (p. 160). Therefore, it seems to be important to not only look at the beliefs teachers hold on mathematics teaching in general, but also at those beliefs teachers develop on a new teaching approach when participating in a professional development course. Unfortunately, so far we only know little about what beliefs mathematics teachers develop about IBL. However, there are some national small scale studies in science education which we will discuss in the following.

Apparently, many science teachers interpret IBL as doing experimental work without any interference by the teacher (Haagen-Schützenhöfer, Rath, \& Rechberger, 2017; Huang, 2015). When we look specifically at the impact of PD on science teachers' interpretations of IBL, we find different results. Huang's study (2015) indicated that the teachers' beliefs on IBL are close to the intended outcome of the PD, which aimed at conveying a picture of IBL as a knowledge building process. As opposed to this, Panjwani's work (2015), which analyzed five science teachers in a qualitative interview study at an international school in Norway, indicated that teachers' beliefs on IBL after the PD differed from the given IBL definition. For example, in their interpretation of IBL, teachers highlighted as an aim students' motivation, but when planning their lesson they often chose teaching examples with a focus on content. This is also in line with the results of Marshall and Smart (2013). They analyzed three cases of science teachers in the USA. Their results pointed to the fact that teachers' IBL interpretation rank from rather superficial understandings with missing specifity to a consistent understanding well-aligned with the given definition. One possible reason for this discrepancy between teachers' understanding of IBL and the conveyed definition of IBL might be found in the complex nature of the IBL teaching approach (Marshall \& Smart, 2015).

When we look at mathematics instead of science we also have to take into account the specific nature of mathematics as a deductive science. Due to its specifities, hands-on activities or inductive conclusions have a less prominent role in mathematics (education) than in science (education). Therefore, the challenge of developing an appropriate interpretation about IBL might be even bigger for mathematics teachers than for science teachers. It is therefore important to have a closer look at the beliefs mathematics teachers develop about IBL in order to close this knowledge gap.

\subsection{Professional Development of Teachers and Implementation in Primas}

The term teacher professional development relates to growth in teachers' content knowledge (knowledge about the subject), pedagogical content knowledge (knowledge about how to teach the subject), and pedagogical knowledge (Shulman, 1986). PD also includes teachers' classroom practice (Clarke \& Hollingsworth, 2002), as well as their beliefs, motivation, and competence in self-reflection (Baumert \& Kunter, 2013).

Within the interconnected model professional (Clarke \& Hollingsworth, 2002, see 2.2) growth can start at any point and ideally involves all four aspects. All growth is situated in an environment of change and therefore, this context influences development. This model shows that PD has to take into account all these facets but as opposed to the linear models of connections between beliefs and practice (see 2.2), does not necessarily have to start off from beliefs to change classroom teaching, or vice versa.

In the last decades, PD research has led to the development of PD itself and related quality criteria. It is now commonly accepted that PD courses should (cf. Barzel \& Selter, 2015):

- take teachers' needs into account (Guskey, 2000)

- $\quad$ combine seminar phases with learning on-job at school (Lipowsky \& Rzejak, 2012);

- $\quad$ be long-term (Tirosh \& Graeber, 2003);

- $\quad$ stimulate cooperation between teachers (Barzel \& Selter, 2015);

- $\quad$ be relevant to teaching practice (Barzel \& Selter, 2015); and

- $\quad$ foster teachers' reflection on their beliefs about mathematics teaching (cf. Tirosh \& Graeber, 2003, Barzel \& Selter, 2015).

The Primas PD model was designed based on the quality criteria described above. In the seminar phases, teachers 
worked on classroom activities that illustrated the pedagogical challenges of IBL and watched other teachers using these same activities through use of video. In the learning on-job phase, teachers were encouraged to adapt and use the activities in their own classrooms. Finally, in the next seminar session, teachers met to share classroom experiences and discuss the pedagogical implications starting off from teachers' beliefs. We repeated this cyclic process at each PD event, as new pedagogical issues were addressed.

We designed the PD activities into seven modules (see Table 1). Modules 1 and 2 introduced teachers to inquiry-based learning. We included tasks with a direct connection to the curriculum (Module 3: Learning concepts through IBL) and also used big projects not directly connected to the content of the curriculum but focused on inquiry competences (see 2.1). In particular modules 4-7 focused on the role of students and teachers as their roles change when doing inquiry (see above). We also explicitly included the inquiry circle in modules 1 and 7 (Table 1).

Table 1. Topics addressed in the Primas PD course.

\begin{tabular}{lll}
\hline 1 & $\begin{array}{l}\text { Student-led } \\
\text { Inquiry }\end{array}$ & $\begin{array}{l}\text { Presenting teachers with phenomena and inviting them to pose and pursue their own } \\
\text { questions (introduction of the inquiry circle). }\end{array}$ \\
\hline 2 & $\begin{array}{l}\text { Tackling } \\
\text { Unstructured } \\
\text { Problems }\end{array}$ & $\begin{array}{l}\text { Comparing structured and unstructured versions of problems and considering the } \\
\text { demands and challenges unstructured problems present in the classroom. }\end{array}$ \\
\hline 3 & $\begin{array}{l}\text { Learning } \\
\text { Concepts through }\end{array}$ & Considering how the processes of IBL might be integrated into the teaching of content. \\
& IBL
\end{tabular}

For example in Module 2 (see table 1) teachers were given the table tennis task as shown in Fig. 2. They were asked to work through the structured problem carefully, list all the decisions that are being made for the students, and revise the problem so that some of these decisions are handed back to students. In the next step, they were asked to discuss pedagogical issues that may arise when using the open version in class and how to overcome them. Next teachers watched a video on the implementation of the problem at school and discussed emerging issues. Afterwards they planned their own lesson with the tennis tournament problem. Back at school they implemented the task. In the next seminar lesson, they presented their lesson, showed student work, and highlighted challenges which were discussed in the group.

We implemented the seven modules in all 12 partner countries. For this, the overall international concept of the Primas PD courses was adapted nationally. However, the adaptations made did not conflict with the overall principles as described above and mainly concerned the organizational framing. In order to ensure quality across countries, we discussed the overall PD principles and their implementation into the PD course at the biannual project meetings. In each country, project partners selected and briefed further math education experts who then ran the courses. In 2012 and 2013, at least 100 teachers in each country took part in the PD courses. As we had to take into account the national contexts in each country for a successful implementation, the actual timeframe varied across countries (from several weeks to a few months). 


\section{Organizing a table tennis tournament}

You have the job of organizing a table tennis tournament.

- 7 players will take part

- All matches are singles.

- $\quad$ Every player has to play each of the other players once.

1. Call the players A, B, C, D, E, F, G.

Complete the list below to show all the matches that need to be played.

$\begin{array}{cr}\text { A v B } & \text { B v C } \\ \text { A v C } & \\ \ldots . & \ldots v \text { B D }\end{array}$

2. There are four tables at the club and each game takes half an hour. The first match will start at 1:00 p.m.

Copy and complete the poster below to show the order of play, so that the tournament takes the shortest possible time. Remember that a player cannot be in two places at once! You may not need to use every row and column in the table!

\begin{tabular}{|l|l|l|l|l|}
\hline Start Time & \multicolumn{4}{|l|}{ Table on which the game will be played } \\
& 1 & & \\
& 1 & & \\
\hline 1:00 p.m. & A v B & & & \\
\hline 1:30 p.m. & & & & \\
\hline 2:00 p.m. & & & & \\
\hline 2:30 p.m. & & & & \\
\hline 3:00 p.m. & & & & \\
\hline 3:30 p.m. & & & & \\
\hline 4:00 p.m. & & & & \\
\hline 4:30 p.m. & & & & \\
\hline
\end{tabular}

Figure 4. Task from Module 2

\section{Methodological Approach}

\subsection{Case Study}

To answer our research questions, we chose a case study approach as this approach aims at obtaining a "rich picture with many different kinds of insights coming from different angles, different kinds of information" (Thomas, 2011, p. 21). With our cases from different countries (see 3.2), we followed a multi-case design, which is often considered to be more robust than a single-case design (Yin, 2010). One of the purposes of our case study was to gain deeper insights into the developing of beliefs of IBL and into the relationship between these interpretations and teachers' perceived classroom practices. As opposed to other methods, within the case study approach the different cases of the multi-case design do not have to fulfill identical contextual conditions, nor must the sample give a complete picture of the whole (Yin, 2010). Therefore, the multi-case study design fit ideally to the project design because partners all implemented PD courses using the same principles and modules, but had to adapt the concept to their national conditions. We used a case analysis which can be carried out across cases independent of whether they are independent research studies or part of the same one (Yin, 2010), as in our case.

Conducting international research can be considered to be more complex than national research. One reason for this is the variability of constraining factors that might be viewed as fixed in a national context, such as language(s) spoken, cultural norms, and understanding of technical terms concerned (Baistow, 2000). Further, due to constraints of time and money, a translation of all qualitative data in an international project is practically impossible (Baistow, 2000) - and there is always the risk of changes in meaning and nuance to the data during translation. Additionally, it was also impossible for one person to centrally collect all data across Europe. Therefore, we decided that each country would collect the data in the nation's language(s), evaluate the collected national data, and then write a case study in English about the results.

We ensured that data collection and evaluation procedures were performed as intended in all partner countries by the 
following means. Firstly, each country appointed a country-evaluation expert experienced in evaluation who carried out data collection (interviews) and evaluation and wrote the case study. For reasons of objectivity, this person was not involved in running the PD courses. All country-evaluation experts jointly formed the project's case study team that was led by the authors of this paper. Secondly, we ensured standardized data collection through standardized semi-structured interview guides and interview training workshops with the country-evaluation experts. We then agreed a common method of evaluation (see below). Finally, we developed a common case study framework with guiding questions for all participants.

\subsection{Sample}

Within the case study approach, the sample is not meant to be representative. It is also not meant to show the quality of the whole (Thomas, 2011). It is rather, as Thomas puts it a choice, or selection. The cases should be selected so as to best illuminate the research questions (Yin, 2010). Therefore, personal knowledge about the potential case is needed in order to select appropriate cases (Yin, 2010). For example, cases can be good examples of something, classical cases, or outlier cases showing something different from the norm.

As the sample does not have to be representative, there is no minimal or maximum size given. The size of the selection should be chosen so as to have the potential to answer the research questions and give a rich picture of the situation (cf. Yin, 2010; Thomas, 2011). We therefore asked all partner countries to select two teachers participating in their PD course so as to have more than one case per country, yet keep the amount of data feasible.

The cases were all teachers who taught students between ages 11 and 19. Most teachers taught both mathematics and science, and only some of them only one of the subjects. Within the project's case study team, we discussed how to select the best possible cases. For example, we could have chosen teachers who teach students of the same age (e.g. 11-12 year old students), or teachers of the same age group etc. However, after careful reflection we decided to follow Yin (2010) and to have country-evaluation experts select classical cases which would best illuminate the research questions based on their knowledge about participating teachers. In this paper we focus on teachers teaching mathematics.

Thus, the cases represented here are classical cases from the national PD courses. Naturally and in accordance with the case study theory (see above), we do not claim our typology to be comprehensive (see results), there might be many more types of teachers' beliefs of IBL. We merely state that these three types seem to exist and that they could be reconstructed across 11 countries.

Table 2 gives an overview of the cases. Naturally, all cases come from different cultural backgrounds, with differences in teaching traditions, initial teacher education, school organization, in-service PD, and curricula (for details see Dorier \& Garcia, 2013; Engeln, Euler \& Maass, 2013).

Table 2. Overview of cases

\begin{tabular}{|c|c|c|}
\hline Country & Case pseudonym & $\begin{array}{l}\text { Case description (gender, experience with IBL } \\
\text { (very little, some, great deal), Age group (e.g. } \\
\text { [40] stands for 36-45), teaching experience) }\end{array}$ \\
\hline CH (Switzerland) & $\begin{array}{l}\text { Jean-Paul } \\
\text { Claude }\end{array}$ & $\begin{array}{l}\text { male, very little, }[50], 3 \text { years } \\
\text { male, very little, }[30], 3 \text { years }\end{array}$ \\
\hline CY (Cyprus) & Mary & female, some, [40], 12 years \\
\hline DE (Germany) & $\begin{array}{l}\text { Johanna } \\
\text { Jan }\end{array}$ & $\begin{array}{l}\text { female, some, [30], } 2 \text { years } \\
\text { male, great deal, [40], } 15 \text { years }\end{array}$ \\
\hline DK (Denmark) & $\begin{array}{l}\text { Uffe } \\
\text { Thomas }\end{array}$ & $\begin{array}{l}\text { male, some, [50], } 6 \text { years } \\
\text { male, very little, [60], } 30 \text { years }\end{array}$ \\
\hline ES (Spain) & Martina & female, very little, [40], 11 years \\
\hline HU (Hungary) & Eva & female, very little, $[50], 20$ years \\
\hline MT (Malta) & John & male, very little, [40], 15 years \\
\hline NL (The Netherlands) & $\begin{array}{l}\text { Ingrid } \\
\text { Henk }\end{array}$ & $\begin{array}{l}\text { female, some, [50], } 20 \text { years } \\
\text { male, some, [50], } 3 \text { years }\end{array}$ \\
\hline NO (Norway) & Stein & male, very little, $[30], 5$ years \\
\hline SK (Slovakia) & $\begin{array}{l}\text { Pavol } \\
\text { Paula }\end{array}$ & $\begin{array}{l}\text { male, very little, }[30], 7 \text { years } \\
\text { female, very little, }[40], 10 \text { years }\end{array}$ \\
\hline UK (United Kingdom) & $\begin{array}{l}\text { Andy } \\
\text { Ben }\end{array}$ & $\begin{array}{l}\text { male, very little, }[30], 4 \text { years } \\
\text { male, some, [40], } 9 \text { years }\end{array}$ \\
\hline
\end{tabular}

The international analysis results we report on here are based on 17 cases across 11 countries from our originally planned 24 cases out of 12 countries. The remaining teachers could not be included because of not having mathematics as a subject (2), withdrawals during the study (3), and local difficulties in obtaining access (2). Due to ethical reasons, participation in the data collection was voluntary. 


\subsection{Data Collection}

Interviews are the most important sources of case study evidence (Yin, 2010). Therefore, for each case we conducted, among others, two interviews (one at the beginning of the PD and the other near the end). The aim of the interviews was to find out how teachers across Europe come to interpret IBL and how these characterizations relate to their perceived IBL enactments. In order to identify possible influencing factors to the research questions, our common, semi-structured interview guide tackled a broader range of aspects (see Annex). The interviews lasted between 30 and 60 minutes.

\subsection{Data Evaluation}

A coded evaluation of the interviews was carried out using a coding approach (cf. Strauss \& Corbin, 1998). We proceeded in three steps.

First, the country-evaluation experts analyzed the transcribed interviews in their languages using open codes and theoretical codes. An open code is a phrase taken directly from the interview text. For example, if a teacher says: "IBL means deeper understanding of content," you can then use "Deeper understanding" as a code. A theoretical code is set up in advance based on theoretical knowledge. For example, based on our definition you could set up the code "IBL means understanding of the nature of mathematics." The authors developed the theoretical codes based on the theoretical background as outlined here in this paper. The theoretical codes regarding teachers' beliefs included their understanding of IBL, different aims seen for IBL, its connection to day-to-day teaching, challenges, and benefits related to IBL. For example, in relation to the aims seen for IBL, we used the codes "motivation," "creativity," "understanding the nature of mathematics," "reasoning," "critical reflection," "interdisciplinarity," "connection to reality," "lifelong learning," "IBL is meaningful," "getting insight into the inquiry process," "process competences," "deeper understanding," and "better prepared for assessment".

Each partner received a list of the codes including explanations. In workshops during project meetings, we discussed the meaning of the codes and also coded parts of the interviews together so as to ensure a common understanding of them.

Second, all country-evaluation experts wrote their case studies based on the common case study framework (not presented here due to its length, but can be provided upon request). These experts are the case study narrators.

Third, the authors analyzed the above mentioned interview section of all case studies comparatively across countries. Consequently, this analysis included the entire case study text including direct quotations from the interviews and the text written by the narrators, which is a common procedure in cross-case analysis of case studies (Yin, 2010). From each case, we wrote a description about main aspects of their beliefs on IBL (Kelle \& Kluge, 1999). We then sorted the cases into groups by looking for commonalities and differences. These comparisons led us to the insight that there were important categories for sorting the IBL interpretations. These categories were the understanding of IBL, aims of IBL, connection of IBL to the curriculum, tasks for IBL, challenges connected to IBL, and perceived enactment of IBL. Sorting the descriptions according to these categories led to three groups as described in results. Thus, we developed "types" (Kelle \& Kluge, 1999) of teachers.

\section{Study Results}

The open data evaluation revealed that, over the course of the PD, teachers in our sample came to characterize IBL in three different ways. Six teachers developed the view that IBL is a peripheral activity mainly to motivate students (type A), five saw IBL as a collection of pedagogical practices designed to promote students' thinking and reasoning (type B), and the remaining six (type C) viewed IBL as a combination of activities and pedagogies intended to develop the capacity of students to engage in scientific processes and to learn scientific content (Table 3). As we shall see, these interpretations became progressively more sophisticated and closer to the intended definition of IBL More interestingly; these interpretations seem to be closely related to the different ways teachers perceived their implementation of IBL in their classrooms.

Table 3 groups teachers according to their reported experiences of IBL prior to the PD. The teachers with little or no prior experience of IBL came to interpret it in each of these different ways, whereas those with some prior experience came to regard IBL as "pedagogies for thinking" or for "scientific processes." The one teacher who had had a great deal of prior experience interpreted IBL as "scientific processes." This would support the view that there is a progression in these interpretations.

The focus of our evaluation was to establish belief types that gradually emerged during the PD and to relate these to the different ways in which teachers enacted IBL. Although this was not our focus, when it came to teachers' beliefs about IBL, we did not discover significant changes in beliefs during the PD course (except for one teacher). 
Table 3. Viewpoints of teachers from the 19 case studies

\begin{tabular}{llll}
\hline $\begin{array}{l}\text { Teachers' prior } \\
\text { experience of IBL }\end{array}$ & $\begin{array}{l}\text { Type A. Peripheral activities for } \\
\text { motivation }\end{array}$ & $\begin{array}{l}\text { Type B. Pedagogical practices } \\
\text { for thinking and reasoning }\end{array}$ & $\begin{array}{l}\text { Type } \begin{array}{c}\text { C. } \\
\text { pedagogies } \\
\text { processes }\end{array} \\
\text { for }\end{array}$ \\
\hline Very little & $\begin{array}{l}\text { Pavol (SK), Paula (SK), Eva (HU), } \\
\text { sartina (ES), Jean-Paul (CH), Claude } \\
\text { scientific }\end{array}$ & Andy (UK), Stein (NO) & Thomas (DK), John (MT) \\
\hline Some & & $\begin{array}{l}\text { Ingrid (NL), Henk (NL), Ben } \\
\text { (UK), Uffe (DK), Mary (CY), } \\
\text { Johanna (DE) }\end{array}$ \\
\hline A great deal & & & Jan (DE) \\
\hline
\end{tabular}

4.1 Type A: IBL as Classroom Activities for Motivating Students

Six of the teachers appeared to create a mental separation between IBL and the rest of their teaching. They viewed their "normal" priority as developing mathematical facts and procedures, whereas they viewed IBL as mainly recreational. For them, the aim of IBL was to develop motivation and, sometimes general thinking processes. For these teachers, teaching content had a higher priority, while IBL was marginalized. For example, Paula seemed to distinguish the "game" and "transmissive" teaching:

"When we want to cultivate the thinking processes the game [IBL] is more effective, and when we want some knowledge that can be measured in a test, then the game is not effective. What do we want at the end, a good result from the test? If we want the student to know the key terms, then we need to teach them that."

Martina from Spain appeared to have a similar perspective.

"The methodology that I usually use in class is to give them [students] exercises, .... From time to time, I propose a game ... that makes them think... and get them out from the daily grind."

These teachers from Slovakia and Spain referred to IBL as a "game" - a recreational activity to make students think and provide relief from the daily "grind." It was common for teachers in this category to refer to the external assessment as defining the curriculum, and thus they relegated IBL as being "extra-curricular" because it is not assessed. These teachers also tended to assume that IBL requires a different kind of task than classical teaching does, namely one that is more substantial, such as extended projects. They saw IBL as difficult to integrate into an already overcrowded curriculum. In this respect, the Hungarian narrator wrote about Eva:

"She considered the [IBL] lesson as very useful with respect to collaborative work...to finding...different creative solutions. However, she expressed her feelings that such tasks can only be used seldom, e.g., at the end of a thematic session. It takes rather much time.... and the tight schedule of the school year does not allow for using inquiry lessons more frequently."

In the same manner, Mary, one of the Cypriot teachers said, "I wish I could use more inquiry in my lessons, but there is so little time for extra-curricular activities."

In summary, in this belief category, IBL is viewed as an approach to the development of motivation and/or process skills that lie outside the teacher's main task, which is to inculcate scientific facts and procedures that will be tested in the examinations. IBL is viewed as requiring additional, time-consuming tasks, such as investigations or extended projects. This viewpoint marginalizes IBL; it becomes an occasional activity that, while worthwhile, is only to be introduced after the serious work of the curriculum is done. Understandably, the teachers in this category perceived fewest changes to their practice.

\subsection{Type B: IBL as Pedagogical Practices for Promoting Thinking and Reasoning}

This group of teachers seemed to consider IBL as a collection of pedagogical practices that may be used at any time, irrespective of the curriculum area being considered. IBL is associated with: open questioning; discussion; dialogic teaching; or group-work designed with the aim to foster students' thinking and reasoning. Often these thinking and reasoning skills were left vague and expressed incoherently. For example, the English narrator reported that Ben considered IBL as an integral part of mathematics learning, "Increasingly, IBL has for him been a way of organizing a pedagogical experience to achieve certain outcomes, rather than a discrete activity to be considered outside the regular curricular framework."

This view does not necessarily associate IBL with extended tasks. The English narrator said of Ben, "One of the key tactics is to adapt quite standard curriculum tasks by making them more open. Asking pupils a more open question, he says, leads to greater engagement." Similarly, Andy said in his interview, "I think that since we started doing this I have been a bit more patient, not rushing to give, [but] holding back and letting them think. I have been doing that quite a bit." 
Even though IBL is viewed as being easily integrated into the curriculum, these pedagogical practices are still perceived as more time consuming than more traditional transmission methods. For example, the narrator from the Netherlands reported, "Both teachers mention that time pressure is sometimes a problem for preparing and conducting IBL. Classroom discussions can be time consuming." However, in contrast to the teachers in group A, group B teachers tended to see the issue of lack of time as a challenge to be overcome, rather than as an immovable obstacle. As Ben said, "So you know you've got to kind of think well, I can't do this all the time because of the volume of time it would take to plan, but we need to fit some in somewhere."

In summary, the type B teachers viewed IBL as a collection of pedagogical practices applicable to all mathematics lessons. This clearly distinguishes type B from type A. However, the type B teachers did not yet appear to have developed a coherent way of organizing these practices into a conceptual framework that may be termed IBL. In general, the teachers in this category said that they changed their teaching to a moderate extent through the course of the PD by incorporating particular pedagogical features into their practice, such as more open questioning or more collaborative discussion. For example, Stein explained:

"Yes, the changes I've made are that I have become more aware of the use of discussion and that I play on student statements. It is important that I allow a student to give the answer instead of giving the answer myself."

\subsection{Type C: IBL as Learning the Processes and Content of Science and Mathematics}

A third group of teachers seemed to have developed a more complex view of IBL than the previous two. They considered IBL as a seminal component of the curriculum requiring a distinct set of tasks pedagogies to develop a coherent set of learning outcomes that are a set of scientific process skills and the learning of scientific content.

Thomas, for example, described IBL as, "It is related to going through the inquiry circle and developing sequences of teaching where one gets all the way round." The Danish narrator further explained that for Thomas, practical work using IBL differed from work where the objective was to demonstrate the correctness of some physical theory. Thomas said he used IBL sessions to teach competencies, such as experimental competency and variable control competences. Apparently, Thomas had a more systematic focus on the goals of IBL. He saw these goals within a coherent framework, the inquiry cycle. Unlike type B teachers, Thomas had a clearer view of intended learning outcomes.

Mary gave an example about how teachers foreground the active role of students in conducting their own investigations, "Inquiry is about giving priority to students to generate explanations and engage in critical discourse...these [activities] include engaging the students in scientific questions, [and] conducting investigations in solving complex problems."

Type $\mathrm{C}$ teachers also did recognize IBL's motivational power, however they saw it as a by-product, and not a main focus. Jan, for example, illustrated how he captured students' interest while they jointly generated questions in his mathematics lessons.

"When I introduced parabolas...we used nerf guns and recorded the trajectory with a camcorder. The pupils could physically see how the trajectory changed. They were asked to estimate the curve's height and the distance flown.... The pupils understood the connection between work angles, distance, and height very soon.... We thought that the IBL way of introducing quadratics helped the pupils to cope much better with the topic itself than it would have been by teaching in the traditional way."

The type $\mathrm{C}$ teachers appeared to believe that IBL should serve like an essential component of a balanced diet as Jan explained, "There are topics where IBL doesn't make any sense. [...] I think it's best if you have a good mix of everything."

Some teachers in this group (e.g. Jan) saw the potential for IBL to enhance conceptual understanding. Others, like Uffe, as the Danish narrator said, thought that, “... the [IBL] task could contribute to the students' learning of important mathematics such as...measuring and calculating with units...and using linear functions to model a practical phenomenon." Teachers in this group also considered a lack of time as a challenge, however as opposed to group A teachers, it did not prevent them from including IBL into their teaching. Instead, they tended to look for strategies to deal with the time issue, as the example of Johanna shows:

"My learning experience is: Simply bearing in mind that there are different tasks than just the standard ones. You invest time, but it makes sense to do so. Also I recognized that not just the mathematical/technical components are important, but on the students' side there is also an increase in other skills."

Other teachers cited the increased understanding that students gain as a sufficient reason to include IBL (e.g. Jan).

To summarize, this view of IBL recognizes that students must actively engage in a complex cycle of scientific processes. Teaching the inquiry cycle is an important, central part of every student's scientific education. While it may not always be possible to teach some aspects of content through inquiry, IBL may motivate and support the learning of content. 
This more sophisticated viewpoint recognizes that content and process may be taught together, task design is important, and that appropriate pedagogies are required. As these teachers considered IBL as a seminal component of the curriculum connected with a coherent set of learning outcomes, they were inclined to find reasons to overcome time issues.

Over the course of the PD, the teachers in this category perceived themselves to have attained a high level of IBL in their thinking and practice. Thomas described his teaching prior to the PD course, "I did not have any experience with the inquiry circle used in the PD-course, but I had used some sub-elements of the circle. I did not think about the process as a complete circle of inquiry." Apparently, the PD course assisted him in his thinking about IBL and he became more focused on using the entire inquiry circle.

\section{Discussion}

\subsection{Contributions to Theory}

This paper contributes to the theoretical discussion regarding mathematics teachers' beliefs and the impact of professional development on IBL, as it contrasts the intended understanding of IBL (as an outcome of a PD course) with the beliefs teachers' develop. The identification of the mathematics teachers' interpretations of IBL is relevant for informing the theoretical discussion, as these beliefs seem to impact the teachers' enactment of IBL in class, at least from the perspective of teachers.

In the following, we will first discuss factors which mediated our results, and afterwards outline consequences for further professional development studies.

The different interpretations of IBL our three types show apparently have been mediated by many different factors. First of all, in this international study we evaluated teachers from 11 different countries. Clearly, the results have been mediated by the national contexts. This is also indicated by our results as shown in Table 3. Here teachers from the same country are found in the same group of teachers. We already pointed out that there are country-specific differences as regards, for example, initial teacher education, PD, and curricula. However, there are also commonalities: A comparative analysis of education documents and curricula showed that in all partner countries, there were explicit signs of evolution in favor of IBL. In some countries, this orientation in pedagogy was quite recent (Cyprus, Germany, Hungary, Malta, Slovakia, Spain, Romania). By contrast in others (England, Norway, the Netherlands, Denmark, Switzerland), there was a long tradition of constructivist pedagogy (Dorier \& Garcia, 2013). This balance between differences and commonalities across countries as observed in Primas is in line with observations from TIMSS (Trends in International Mathematics and Science Study): "Even though teaching in a given country may exhibit a common pattern [...] and there was some convergence across all countries." (Givvin et al. 2005)

Naturally, these interpretations of IBL have not only been mediated by teachers' national contexts, but also by the actual length of the course, the multiplier who ran the PD course, the school context the teacher works in (Joubert \& Southerland, 2009), and also their prior beliefs on mathematics (Maass, 2011). More research is needed to evaluate more specifically how these factors mediate the specific interpretations.

Apart from these factors which may differ from teacher to teacher, we need to be aware that teachers interpretations surely also have been influenced by our IBL definition, as well as the PD course design. This leads to important consequences for future professional development on IBL, which we will outline now.

We will have a look at our definition of IBL (see 2.1) first. When we compare the aims the three types see for IBL with our definition, and in particular with the section "valued outcomes," we can identify important differences. We can see that type A apparently did not internalize the "valued outcomes," as these teachers mainly referred to motivation and only sometimes to general thinking processes. Additionally, they did not seem to consider these outcomes to be as important as the learning of content. Type B seemed to focus more on pedagogical practices and thereby, apparently took over aspects of the definition which are expressed in the sections "teachers' guidance," "classroom culture," "types of questions," and "what students do," but much less on the specific "valued outcomes" like inquiring minds, preparing students for an uncertain future, and lifelong learning and understanding the nature of mathematics. Only type C seemed to have internalized these valued outcomes. In their descriptions of their interpretation of IBL these teachers referred to scientific process skills and to the inquiry circle and hereby, to exploring situations, asking questions, seeking for explanations, and so forth. Additionally, some of these teachers referred to a deeper understanding of mathematical content.

The definition we gave to teachers was intended to be pragmatic and useful for teachers and to convey an unambiguous picture of IBL. Nevertheless, it apparently allowed for the three different interpretations. The three groups seemed to have a different focus on the "valued outcomes." Type A seemed to more or less ignore them, type B seemed to focus on pedagogical practices, whilst only type $\mathrm{C}$ seemed to have a concrete understanding of them. Building on these insights, 
we would change the definition for future PD: It might be useful to alter the valued outcomes in the definition to have more concrete and clear outcomes that are more easily accessed by teachers, such as: deeper understanding of content knowledge, knowledge on inquiry processes as carried out by mathematicians, and knowledge on how to use mathematics content in inquiry-processes.

Furthermore, in a future PD course, we would put more emphasis on the reflection of beliefs about IBL. As was described above (see 2.3) we explicitly included reflection on teachers' beliefs into the design of the course. However, we focused on teachers' beliefs on mathematics education in general and did not reflect on teachers' beliefs on IBL. Based on the insights gained in this study, we would change this.

This insight also leads to consequences for the theory-based quality criteria for professional development courses (see 2.2) and therefore again contributes to theory-building. We would suggest changing the criterion "foster teachers' reflection on their beliefs about mathematics teaching and their teaching experiences" (see 2.3) to "foster reflection on their beliefs about mathematics and teaching experiences and in particular about the teaching approach to be conveyed."

Naturally, our results are in line with other studies which pointed out a close connection between beliefs and teaching (e.g. Roesken-Winter, Schüler et al., 2015). In accordance with the interconnected model from Clarke and Hollingworth (2002), we can conclude that teachers' beliefs are indeed a factor influencing the outcomes of a PD course. However, our study goes beyond these results by showing how the beliefs of the teaching approach at hand (here IBL) may influence the (perceived) day-to-day teaching and therefore need to be considered in the design of a related PD course (see below).

In line with related studies in science education, our results show that the real outcome does not always conform to the intended outcome (Marshall \& Smart, 2013, Panjwani, 2015). Also in line with Marshall and Smart 2013, our study indicates that teachers' interpretations after a PD can vary from more superficial to more sophisticated interpretations. However, our study goes beyond the above mentioned studies for the following reasons: (1) it relates to mathematics teachers; (2) it is an international study and therefore has a broader research basis; and (3) the explorative character of the study allowed reconstructing three different types of interpretations we did not know about before. As the reconstruction of these three types is based on 17 cases from 11 countries they are naturally not comprehensive and there might well be other cases, but the study shows that at least these three types exist.

\subsection{Limitations and Further Research}

This study is only small-scale and so we cannot claim that these three perspectives on IBL we found are the only perspectives teachers may develop. Further larger scale studies might be necessary for this.

Further, to keep this international study feasible we looked at two teachers per country. This sample size did not allow for a comparative study across countries and therefore we treated all case studies from different countries as one sample. Thus, we can consider our study as an explorative study. A future study with bigger sample sizes within the countries would allow for cross-country comparison.

To collect the data and write the case studies for the different countries we had to rely on different country-evaluation experts. Although we took measures to ensure comparability, it might be valuable to carry out a similar study in one country, thus without language difficulties, and compare the results with the study at hand.

This study relies on self-reports of teachers in interviews. To obtain a much more in-depth look into impacting factors, a study taking into account the PD course leaders, their beliefs, and their teaching would be worthwhile.

Additionally, in further research the mediating factors as outlined above, e.g. the country specific contexts, the school context, etc., could be included in the study, for example in a study involving only two countries.

To deepen insights into belief structures and their connections (Green, 1971), a study researching teachers' beliefs about IBL and about mathematics education in general would be required. Thus, the study indicates important directions for future research.

Summing up, this paper contributes to the theoretical discussion regarding the implementation of IBL into day-to-day mathematics teaching practice as it contrasts the intended understanding of IBL (as an outcome of a PD course) with the beliefs teachers' develop. The results of our study highlight the necessity to take into account not only teachers' beliefs on mathematics education in general, but also the beliefs they develop for the teaching approach at hand. As these beliefs also seem to influence teachers' (perceived) enactment of IBL, they need to be considered in the design of a related PD course. By this, we also contribute to the further development of theory-based quality criteria on professional development. 


\section{References}

Alfieri, L., Brooks, P., Aldrich, N., \& Tenenbaum, H. (2011). Does discovery-based instruction enhance learning? Journal of Educational Psychology, 103(1), 1-18. https://doi.org/10.1037/a0021017

Anderson, R. D. (2002). Reforming science teaching: What research says about inquiry. Journal of Science Teacher Education, 13(1), 1-12. https://doi.org/10.1023/A:1015171124982

Artigue, M., \& Blomhoej, M. (2013). Conceptualising inquiry based education in mathematics. ZDM, 45(6), 797-810. https://doi.org/10.1007/s11858-013-0506-6

Baistow, K. (2000). Cross-national research: What can we learn from Inter-country comparisons? Social Work in Europe, 7(3), 8-13.

Barrow, L. H. (2006). A brief history of inquiry: from Dewey to Standards. Journal of Science Teacher Education, 17, 265-278. https://doi.org/10.1007/s10972-006-9008-5

Barzel, B., \& Selter, C. (2015). Die DZLM-Gestaltungsprinzipien für Fortbildungen - Review der Forschungslage und konkretisierende Beispiele. [Design principles for professional development-a review of the state of the research and concrete examples.] JMD, 36(2), 259-284. https://doi.org/10.1007/s13138-015-0076-y

Baumert, J., \& Kunter, M. (2013). The COACTIV model of teachers' professional competence. In M. Kunter, J. Baumert, W. Blum, U. Klusmann, S. Krauss \& M. Neubrand (Eds.), Cognitive activation in the mathematics classroom and professional competence of teachers. Results from the COACTIV Project (pp. 29-55). Mathematics Teacher Education, Vol. 8. Berlin: Springer.

Bruder, R., \& Prescott, A. (2013). Research evidence on the benefits of IBL. ZDM, 45(6), 811-822. https://doi.org/10.1007/s11858-013-0542-2

Clarke, D., \& Hollingsworth, H. (2002). Elaborating a model of teacher professional growth. Teaching and Teacher Education, 18, 947-967. https://doi.org/10.1016/S0742-051X(02)00053-7

Dewey, J. (1916). Democracy and education. New York: Macmillan.

Dorier, J. L., \& García, F. J. (2013). Challenges and opportunities for the implementation of inquiry-based learning in day-to-day teaching. ZDM, 45(6), 837-849. https://doi.org/10.1007/s11858-013-0512-8

Dorier, J., \& Maaß, K. (2012). Inquiry based Mathematics education. Encyclopedia of Mathematics education. Heidelberg: Springer.

Engeln, K., Euler, M., \& Maass, K. (2013). Inquiry-based learning in mathematics and science: A comparative baseline study of teachers' beliefs and practices across 12 European countries. ZDM, 45(6), 823-836.

https://doi.org/10.1007/s11858-013-0507-5

Furinghetti, F., \& Pehkonen, E. (2002). Rethinking characterisations of beliefs. In G. Leder, E. Pehkonen, \& G. Törner (Eds.), Beliefs: A Hidden Variable in Mathematics Education? (pp. 39-57). Dordrecht: Kluwer Academic Publishers.

Givvin, K., Hierbert, H., Jacobs, J., Hollingsworth, H., \& Gallimore, R. (2005). Are There National Patterns of Teaching? Evidence from the TIMSS 1999 Video Study. Comparative Education Review, 49(3), 311-343. https://doi.org/10.1086/430260

Green, T. (1971). The activities of teaching. McGraw-Hill, New York.

Guskey, T. R. (2000). Evaluating professional development. Thousand Oaks: Corwin Press.

Haagen-Schützenhöfer, C., Rath, G., \& Rechberger, V. (2017). Teachers' Beliefs About Subject Specific Competences and Inquiry Based Learning. In T. Greczyło, \& E. Dębowska (Eds.). Key Competences in Physics Teaching and Learning, New York: Springer, 177-190. https://doi.org/10.1007/978-3-319-44887-9_15

Hmelo-Silver, C. E., Duncan, R. G., \& Chinn, C. A. (2007). Scaffolding and achievement in problem-based and inquiry learning: A response to Kirschner, Sweller, and Clark (2006). Educational Psychologist, 42(2), 99-107. https://doi.org/10.1080/00461520701263368

Hoyles, C. (1992). Mathematics teaching and mathematics teachers: A mea-case study. For the Learning of Mathematics, 12(3), 32-44.

Huang, C. (2015). Elementary Teachers' Beliefs about and Implementation of Inquiry-Based Science Teaching. Ontario Institute for Studies in Education of the University of Toronto.

Joubert, M., \& Sutherland, R. (2009). A perspective on the literature: CPC for teachers of mathematics. National Centre 
for Excellence in the Teaching of Mathematics.

Kelle, U., \& Kluge, S. (1999). From individual case to type. Opladen: Leske und Budrich.

Lipowsky, F., \& Rzejak, D. (2012). Lehrerinnen und Lehrer als Lerner - Wann gelingt der Rollentausch? Merkmale und Wirkungen wirksamer Lehrerfortbildungen. [Teachers as learners - when will the role exchange work?] Schulpädagogik heute, 3(5), 1-17.

Maass, K. (2009). What are German Teachers' beliefs about effective mathematics teaching? In J. Cai, G. Kaiser, B. Perry \& N. Y. Wong (Eds.), Effective Mathematics Teaching from Teachers' Perspectives: National and Cross-National Studies. New York: Sense Publisher.

Maass, K. (2011). How can teachers' beliefs affect their professional development? ZDM, 43(4), 573-586. https://doi.org/10.1007/s11858-011-0319-4

Maass, K., \& Doorman, M. (2013). A model for a widespread implementation of inquiry-based learning. ZDM, 45(6), 887-899. https://doi.org/10.1007/s11858-013-0505-7

Marshall, J. C., \& Smart, J. B. (2013). Teachers' Transformation to Inquiry-Based Instructional Practice. Creative Education, 4(2), 132-142. https://doi.org/10.4236/ce.2013.42019

Minner, D., Levy, A., \& Century, J. (2010). Inquiry-based science instruction - what is it and does it matter? Results from a research synthesis years 1984 to 2002. Journal of Research in Science Teaching, 47(4), 474-496. https://doi.org/10.1002/tea.20347

Mullis, I. V. S., Martin, M. O., \& Foy, P. (2008). TIMSS 2007 International Mathematics Report: Findings from IEA's Trends in International Mathematics and Science Study at the Fourth and Eighth Grades. Chestnut Hill: TIMSS \& PIRLS International Study Center, Lynch School of Education, Boston College.

National Research Council (1996). National Science Education Standards. National Academy Press, Washington, DC.

National Research Council (2000). Inquiry and the national science education standards. Washington, DC: National Academy Press.

Panjwani, N. (2015). Teachers' view on inquiry-based learning in science. Norwegian University of Technology and Science.

Pehkonen, E., \& Törner, G. (1996). Mathematical beliefs and different aspects of their meaning. Zentralblatt für Didaktik der Mathematik, 28(4), 101-108.

Rocard, M., Csermely, P., Jorde, D., Lenzen, D., Walberg-Henriksson, H., \& Hemmo, V. (2007). Science Education Now: A Renewed Pedagogy for the Future of Europe. Luxembourg: European Commission Publications Office.

Roesken, B., Pepin, B., \& Törner, G. (2011). Beliefs and beyond: Affect and the teaching and learning of mathematics. $Z D M, 451-455$. https://doi.org/10.1007/s11858-011-0354-1

Roesken-Winter, B., Schüler, S., Stahnke, R., \& Blömeke, S. (2015). Effective CPD on a large scale: examining the development of facilitators. ZDM, 47(1), 13-25. https://doi.org/10.1007/s11858-014-0644-5

Roesken-Winter, H. C., \& Blömeke, S. (2015). Evidence- based CPD: Scaling up sustainable interventions. ZDM, 47(1), 1-12. https://doi.org/10.1007/s11858-015-0682-7

Schoenfeld, A. (1992). Learning to think mathematically: Problem solving, metacognition and sense-making in Mathematics. In D. Grouws (Ed.), Handbook for Research on mathematics teaching and learning (pp. 334-370). New York.

Schoenfeld, A. (2011). How We Think - A Theory of Goal-Oriented Decision Making and Its Educational Applications. New York: Routledge.

Sewall, G. (2000). Lost in action. American Educator, 24(2), 4-9.

Shulman, L. S. (1986). Paradigms and research programs in the study of teaching: a contemporary perspective. In M. C. Wittrock (Ed.), Handbook of research on teaching (pp. 3-36). New York: Macmillan.

Sowder, J. (2007). The mathematical education and development of teachers. In F. K. Lester (Ed.), Second handbook of research on mathematics teaching and learning: A project of the National Council of Teachers of Mathematics (pp. 157-224). Charlotte, NC: Information Age Publishing.

Stahnke, R., Schueler, S., \& Roesken-Winter, B. (2016). Teachers' perception, interpretation, and decision-making: a systematic review of empirical mathematics education research. ZDM, 48(1), 1-27.

https://doi.org/10.1007/s11858-016-0775-y 
Stigler, J. W., Gonzales, P., Kawanaka, T., Knoll, S., \& Serrano, A. (1999). The TIMSS Videotape Classroom Study: Methods and Findings from an Exploratory Research Project on Eighth-Grade Mathematics Instruction in Germany, Japan, and the United States (NCES 1999-074). Washington, DC: National Center for Education Statistics.

Strauss, A., \& Corbin, J. (1998). Basics of qualitative research. Thousand Oaks, CA: SAGE Publications.

Swan, M. (2005). Improving Learning in Mathematics: Challenges and Strategies. Sheffield: Teaching and Learning Division, Department for Education and Skills Standards Unit.

Swan, M. (2006). Collaborative Learning in Mathematics: A Challenge to our Beliefs and Practices. London: National Institute for Advanced and Continuing Education (NIACE) for the National Research and Development Centre for Adult Literacy and Numeracy (NRDC).

Swan, M. (2007). The impact of task-based professional development on teachers' practices and beliefs: A design research study. Journal of Mathematics Teacher Education, 10(4-6), 217-237. https://doi.org/10.1007/s10857-007-9038-8

Swan, M., \& Swain, J. (2010). The impact of a professional development programme on the practices and beliefs of numeracy teachers Journal of Further and Higher Education, 34(2), 165-177. https://doi.org/10.1080/03098771003695445

Thomas, G. (2011). How to do your Case Study. A guide for students and researchers. Thousand Oaks, CA: Sage.

Tirosh, D., \& Graeber, A. O. (2003). Challenging and changing mathematics teaching practises. In A. Bishop, Clements, M.A., Keitel, C., Kilpatrick, J., Leung, F. (Ed.), Second international handbook of mathematics education (pp. 643-688). Dordrecht, Boston, London: Kluwer Academic Publishers. https://doi.org/10.1007/978-94-010-0273-8_22

Törner, G. (2002). Epistemological fundamental beliefs - hidden variables in teaching and learning of mathematics. Der Mathematikunterricht, 4-5, 103-128.

Yin, (2013). Case study research. Thousand Oaks, CA: Sage.

\section{Annex}

\section{Semi-structured interview guide}

Biography

1. Why did you choose to become a teacher? How long have you been teaching? Subjects? Mathematics and science teaching

2. Which way of teaching do you consider to be most effective? Why?

3. What are the three most important characteristics of an effective educator/teacher?

4. Describe a good lesson, explain why it was/is good.

5. What is important about mathematics and science?

6. When teaching maths/science to your class, what activities occur in your lesson?

7. What are the most important activities for students in your class?

8. What should students learn in mathematics/science education?

9. What teaching materials/tasks have you found to be educationally useful in the classroom? Why?

IBL

10. Please comment on weak and strong points of the instant task. (task: table tennis)

11. In relation to the PD course, are there any changes in your repertoire for promoting IBL? Which?

12. What are the main aspects of IBL? Name the key features of IBL.

13. How much experience do you have working with IBL tasks? What's difficult/easy? Give examples.

14. In how far do you consider yourself prepared for teaching IBL?

15. In relation to the implementation of IBL, describe some of your experiences when collaborating with other staff members. Are your colleagues used to IBL? 
Students and IBL

16. In your own words, how do students get on with the implementation of IBL in the classroom? What is easy/difficult for them? In your opinion, do they like IBL tasks? Why?

17. Describe a few ways that you can positively influence and assist your students in relation to their learning behaviour/study habits?

18. How do you motivate students to become active learners in your classroom?

\section{Copyrights}

Copyright for this article is retained by the author(s), with first publication rights granted to the journal.

This is an open-access article distributed under the terms and conditions of the Creative Commons Attribution license which permits unrestricted use, distribution, and reproduction in any medium, provided the original work is properly cited. 